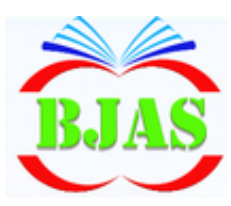

Available online at $\underline{\text { http://journal.bajas.edu.iq }}$

College of Agriculture, University of Basrah

DOi:10.21276/basjas

ISSN $1814-5868$

Basrah J. Agric. Sci., 32(1): 62-67, 2019
Basrah Journal

of Agricultural

Sciences

E-ISSN: 2520-0860

\title{
Experimental infection of native chicken with cattle tick Rhipicephalus (Boophilus) annulatus (Acari: Ixodidae)
}

\author{
Bahzad H. S. Mustafa \\ Department of Animal Science, College of Agricultural Sciences, University of Sulaimani, \\ Sulaimani, Iraq \\ *Corresponding author e-mail: bahzad.Mustafa@univsul.edu.iq
}

Received 13 March 2019; Accepted 21 May 2019; Available online 25 May 2019

\begin{abstract}
Rhipicephalus (Boophilus) annulatus is considered as one of the most widespread tick species of the world on several host including cattle. The current study has been conducted to evaluated infestation ability of larval $R$. annulatus on chicken growth and development, Indicated very few larvae quested or fed on indigenous adult chickens when comparison with the number of larvae which used in this study, and that the larval and nymph feeding period of these ticks was very long. The number of larvae feeding shows in hollows wings, while the number of feeding nymph investigate on head, wings and above of thigh, both larvae and nymph described on the same individual adult chicken, the engorged adult female not observed while the adult male notice on chickens. Designated the weight of feeding larvae and nymphs stage is $0.32 \pm 0.04 \mathrm{mg}$ and nymph's $2.73 \pm 1.22 \mathrm{mg}$. The weight of larvae and nymph stage under mattress and feeder's chicken $0.27 \pm 0.21$ and $2.52 \pm 1.75 \mathrm{mg}$ respectively, shows not significantly when compared between the weight of feeding on chickens and the weight under mattress and feeder's chicken by larvae and nymphs stage at $(\mathrm{P}<0.05)$ values according chi-square. Experimental study shows not transmissions pathogens from incubating larvae, which got from engorged female infested with Babesia spp., to adult chickens when examined their blood by Giemsa stain.
\end{abstract}

Keywords: Rhipicephalus (Boophilus) annulatus, Infected engorged female, Babesia spp., Native adult chicken.

\section{Introduction}

Hard ticks (Acari: Ixodidae) have a significant impact on public health and the rural economy in many parts of the world (Parola \& Raoult, 2001; Jongean \& Uilenberg, 2004). Rhipicephalus annulatus (formerly Boophilus annulatus) is a hard tick found most often on cattle, heavy tick burdens on animals can decrease production and damage pelts (Peter et al., 2005). Rhipicephalus annulatus is an economically important ticks which transmitted parasitic diseases for a variety of livestock; it is known as the cattle tick or southern cattle tick, the most important vectors of disease-causing pathogens in domestic and humans. It is transmitted many babesiosis pathogens like Babesia bigemina, $B$ bovis, 
and Anaplasma marginale (Antunes et al., 2012).

There are a number of species of ticks infesting poultry, the recently of these include; Haemaphysalis punctata, Hyalomma lusitanicum and Ixodes frontalis (Calvete et al., 2003), Amblyomma americanum and Ixodes brunneus have been found on wild turkeys Meleagris gallopavo (Scott et al., 2010). Among the Ixodidae, described Ixodes species are strictly parasitic on birds, Amblyomma species have immature that feed on birds. Haemaphysalis strictly parasites of ground-feeding birds and in nesting birds and no Hyalomma are dependent on birds, although immature Hyalomma species frequently feed on them as well as on mammals, although a few Rhipicephalus species occasionally are found on large ground-feeding birds such as ostrich. None of the other Rhipicephaline genera parasitise birds (Oliver, 1989). The infected birds may transmit a tick-borne disease to the ticks, and the alternative where ticks may transmit pathogens to each other by co-feeding (Hubalek, 2004). Transovarial pathogens passage of Babesia spp from female $R$. annulatus during oviposition. Kinetes of Babesia were present in eggs laid at a suitable temperature (Ouhelli \& Schein, 1988).

The aim of curret study to evaluate Boophilus spp., experimentally for growth and ability this genus to transmit pathogens on native adult chickens.

\section{Materials and Methods:}

\section{Study area}

The current study was conducted at Bkrajo farm- Animal Sciences Department, College of Agriculture, University of Sulaimani.

\section{Ticks collection and identifications}

The engorged female of $R$. annulatus removed by using tweezers and alcohol from different part of cattle body from various flock, collected ticks stored in sterile glass (Bijou tube) for isolation and identifications. (Walker et al., 2003).

\section{Hemolymph (Hemocyte slides) Smear}

Fifty adult female of Rhipicephalus species have been used for detection of pathogens (Piroplasmosis), collected by severing the forelegs at the coxal-trochanteral joint and drawing hemolymph into a glass micropipette. For the purpose of light microscopy of hemocytes, hemolymph was smeared on a glass slide, immediately dried, and fixed in methanol for $10 \mathrm{~min}$. The specimens were stained with Giemsa stain $10 \%$ for $10 \mathrm{~min}$. Exanimation under a light microscope with high was followed 100X (Mustafa, 2011).

\section{Incubations stage}

The pathogenic females (10 engorged females of $R$. annulatus) were allowed to oviposit for 14 days, the weight of engorged females and mass of deposited eggs was done by electronic analytical balance (Mettler-Toledo, Switzerland), and returned to the incubator at $27 \pm 1.6^{\circ} \mathrm{C}$ with relative humidity (RH\%) $85 \pm 1.4 \%$ (Mustafa, 2011).

\section{Chicken preparation to study}

Chickens were used as a laboratory model to determine the conditions that ability of infection with larvae/ticks. Using only 30 native chickens non-infested with ectoparasites (depending on clinical signs and examination) putting in the room $3 \mathrm{~m}^{2}$ during the study to experimental infestation with a proximally 10000 larvae (as average 800-1150 larvae/ engorged female) which was got by incubation 10 engorged female $R$. annulatus and placed on the room's floor to estimate of feeding status.

\section{Larvae and nymph stage weight}

Isolation 30 of adult chickens infested experimentally with $R$. annulatus, for each stage for weighting; larvae and lymph which collected randomly on body chicken during the feeding period and engorged larvae and nymph found under mattress and feeder's chicken by using tweezers and alcohol.

\section{Blood smear preparation}

Using one drop of blood was drawn from wing vein to prepare blood smear for examining and investigating the presence of 
piroplasmosis by light microscope use oil immersion.

\section{Statistical Analysis}

In this study, statistical tests were performed according to chi-square test between two different stage; larvae and nymph weights of $R$. annulatus.

\section{Results}

Three genera of Ixodidae family have been isolated and identified from local cattle at different areas in Sulaimani province; these genera were Rhipecephilus with the highest isolation rate, followed by the genus Haylamma. R. annulatus has been identified and used in artificial infestation of adults chickens (30 adults chicken have been applied with approximately 10000 larvae. Detected very few larvae quested or fed on native adult chickens when comparison with the number of larvae which used in this study. The attachment period of larvae in common was less than 12 hours, the number of chickens infested with unfed larvae increased in the first day and reached the top in 8 days and starts to decline, while the feeding larval starts to increase until 11 days and reached and lost in 16 days, the number of feeding larvae investigate in hollows wings site. The number of unfed larvae on the chicken body was higher than the number of fed larvae; this may be that the blood of chicken wasn't preferable for $R$. annulatus, as shown in Fig. (1). Results showed that the number of nymphs was lower than the number of larvae which feeding on chicken. Fed and unfed larva in age 17 days disappeared may be because some of these larvae enter the dispose stage.

Observed lowest number of nymph quested or fed on indigenous adult chickens when comparison with the number of larvae which used in this work, the cycle of nymph feeding on chicken reached to 15 days (16-30 days as shown in the diagram), the number of feeding nymph appeared on head, wings and above of thigh, the different site of feeding on the chickens may interfere with tick development. Observed the number of infested chickens with unfed and feeding nymph starts in 16 days and reaches the top in 23 days, the cycle of this stage reaches to 14 days (in 17 days to 30 days). Both feeding larvae and unfed nymph described on the same individual adult chicken, the number of unfed nymph on the chicken body was higher than the number of fed nymph. The number of infested chickens was higher than the unfed and feeding nymph. The engorged adult female was not observed while the adult male noticed on chickens. Presence of a number of engorged larvae and nymphs stage under mattress and feeders chicken to enter the dispose stage as shown in Fig. (2).

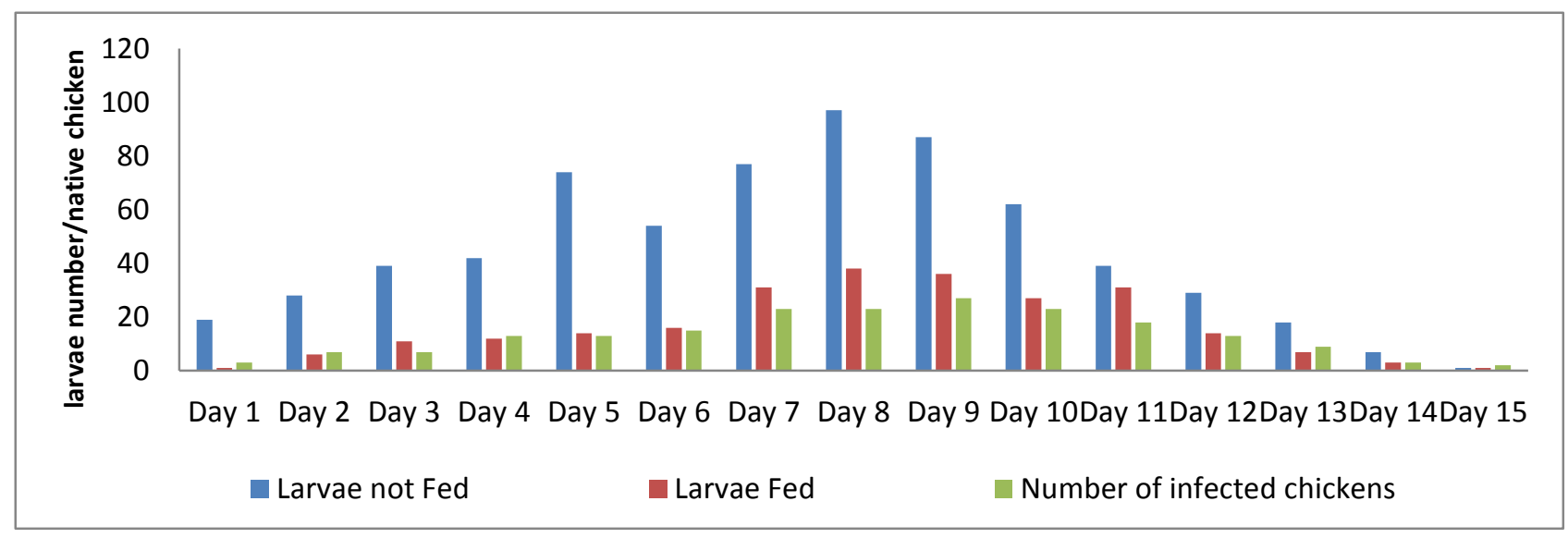

Fig. (1): Biological generation of $R$. annulatus larvae (fed and unfed stages) on adult chickens infested experimentally. 


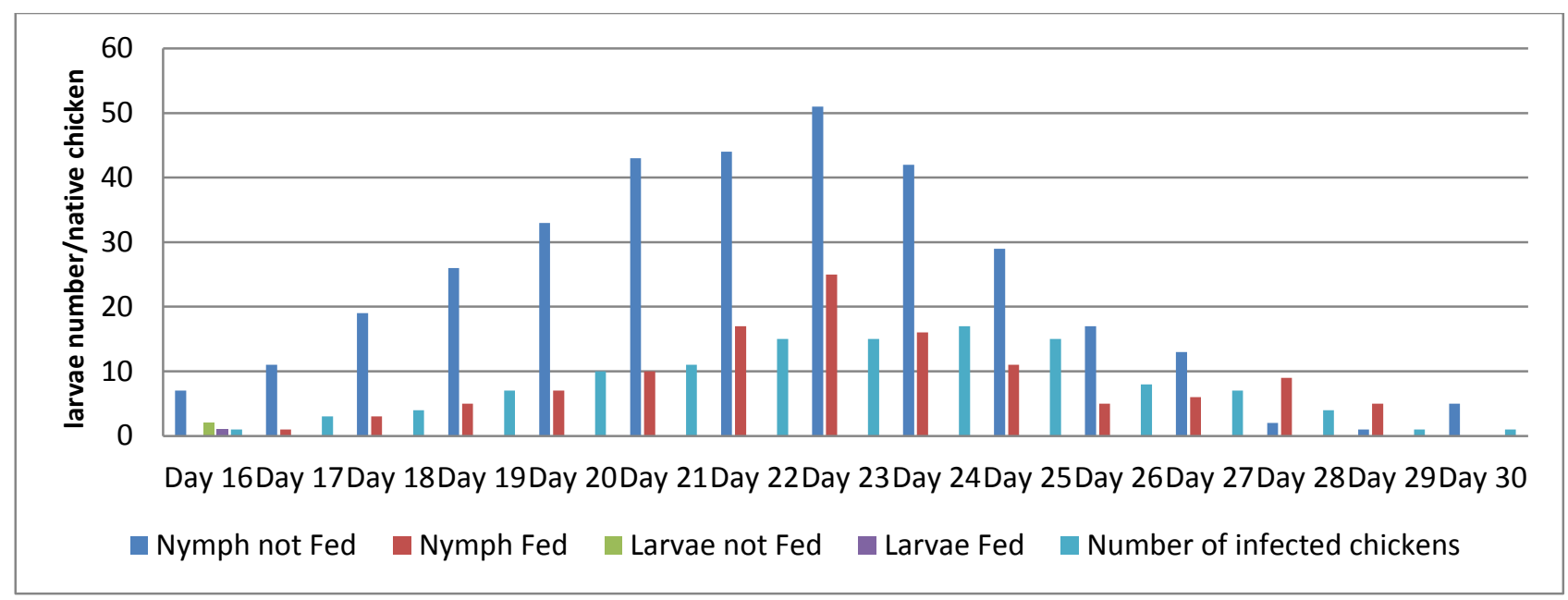

Fig. (2): Biological generation of $R$. annulatus nymph (fed and unfed stages) on adult chickens infested experimentally.

During the study showed the weight of feeding larvae reached to $0.32 \pm 0.21 \mathrm{mg}$ along the feeding period on adult chickens and $0.27 \pm 0.04 \mathrm{mg}$ when examined under mattress and feeders chicken. In nymph stage the weight of feeding nymph reached to
$2.73 \pm 1.75 \mathrm{mg}$, while the weight of nymph appeared under mattress and feeders $2.52 \pm 1.22 \mathrm{mg}$, without any significant differences-according chi-square between two stages weight; larvae and nymph as shown in Fig. (3).

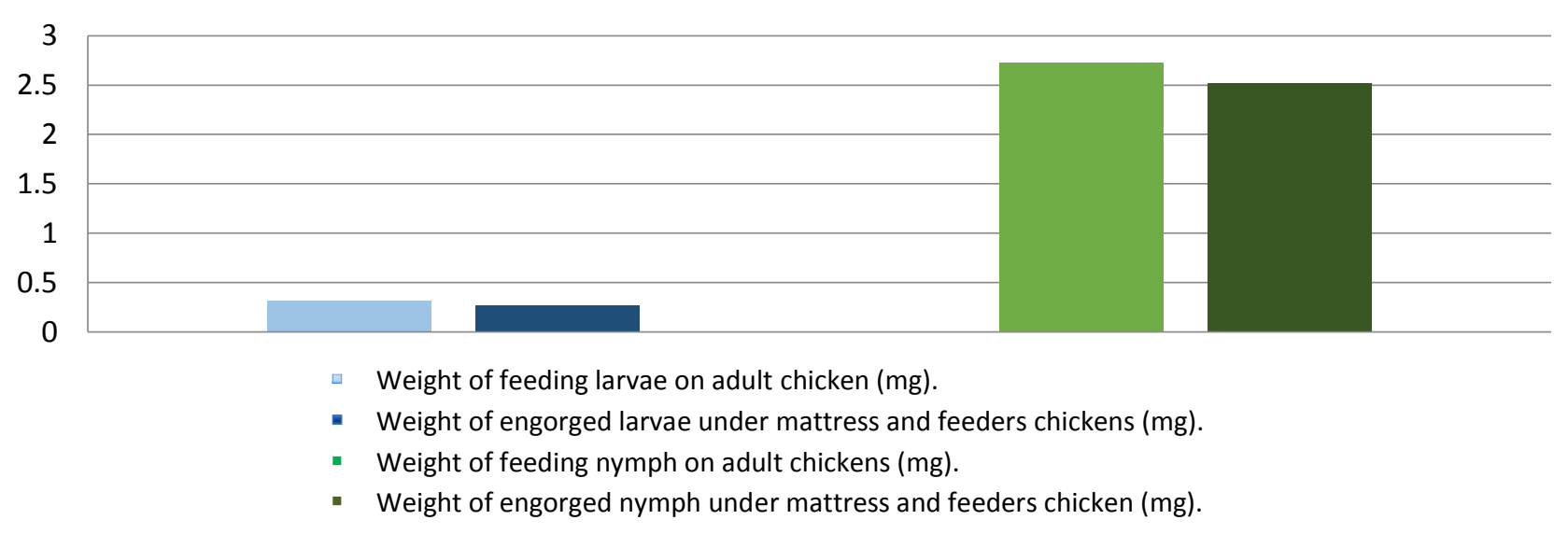

Fig. (3): Weighting of larvae and nymph feeding with $R$. annulatus on adult chicken.

\section{Discussion}

The current research showed the high occurrence of $R$. annulatus than other species at different regions in Sulimania province; this result was in a good agreement with the results of Hasson (2012) when they proved that the species of $R$. annulatus was higher than B. kohlsi. Results showed that adult chicken were unsuitable hosts (very low infestation to larvae and nymph to $R$. annulatus, although showed feeding on the blood chickens. These results in contrast with
Tuama et al. (2007) results which proved the isolation of $30 \%$ of hard ticks infested on chicken and $3.3 \%$ infested with $R$. annulatus. The prevalence of tick infestation on the birds showed a variation between the different studies. The different bird species feeding habits in ground feeding or not (Mehl et al., 1984. Hasle et al., 2009), age of the bird (Scharf, 2004) and season (Hoogstraal et al., 1963; Olsen et al., 1995) have an influence on the prevalence of tick infestation. Feeding 
period in larvae and nymph stage was longest; 16 and 15 days respectively and isolation randomly larvae feeding stage from chicken for weighing, showed the weight of feeding larvae and nymph were $0.27 \pm 0.04$ and $2.52 \pm 1.22 \mathrm{mg}$ respectively, while the weight of larvae and nymph when examined under mattress and feeders chicken were $0.32 \pm 0.21$ and $2.93 \pm 1.75 \mathrm{mg}$ respectively, the difference between the values were not significantly. The weight of larvae and nymph in rabbits were $0.58 \pm 0.09$ and $15.8 \pm 1.4 \mathrm{mg}$ respectively when infested experimentally with Hyalomma truncatum (Rechav \& Fielden, 1997). The larvae and nymph period fed on the rabbits were $4.7 \pm 1.2$ and $9.6 \pm 2.2$ days respectively. Oliver (1989) indicated that the larval and nymphal ixodids feeding on warm blooded animals usually require 3-7 and 4-8 days respectively.

At the same time, the higher number of feeding larvae showed on wings, whereas feeding nymph examined on head, wings and above of thigh, the different site of feeding on the chickens may interfere with tick development (suitable condition including temperature and humidit, Hasson, 2012) infestation percentage of hard ticks on chicken were $30 \% ; 3.3 \%$ of them were $R$. annulatus, the engorged adult female wasn't observed while the adult male noticed on chickens and investigate a number of engorged larvae and nymphs stage under mattress and feeders chicken this could be attributed to the fact that the male nymphs didn't require blood for molting and feeding on skin crusts for their growth and development. Experimental study showed no transmission of trans-ovarially of Babesia spp. to adult chicken, this results agreement with Hasle, (2013) \& Hamsíkova et al. (2016) when they didn't show any Babesia spp. positive in birds. Birds contribute to the geographic distribution of various tick-borne pathogens and serve as their hosts. In Europe, $B$. microti, $B$. venatorum, and $B$. divergens have been found in ticks infesting birds (Toma, et al., 2014). The occurrence of Babesia spp. in ticks (especially in larvae) from birds suggested that birds may be able to infect ticks (Hasle, 2013). Although studies on this topic are lacking in Iraq and especially in Kurdistan region, birds may act as carriers for Babesia-infected ticks contributing to the dispersal of the hard ticks

\section{Conclusion}

The study revealed that native poultry (local Adult chicken) that feed on the ground, are particularly prone to carry ticks and a risk source for the presence of a number of engorged larvae and nymphs stage, subsequently which infect the final host such as sheep and goats and as especially cattle. The ability of $R$. annulatus larvae on the feeding of chicken blood. These results suggest investigations on epidemiological aspects of tick infestation in poultry in the Kurdistan region as the specialist and Iraq as a general should be carried out to provide an effective to control, which is considered the intermediate stage for the growth to the final host.

\section{Acknowledgements}

I am indebted to the deanery of Agriculture Sciences Engineering, Department of Animal Science and Bakrajo farm workers for helping to complete this research.

\section{References}

Antunes, S.; Galindo, R.; Almazán, C.; Rudenko, N.; Golovchenko, M.; Grubhoffer, L.; Shkap, V.; La Fuente, V.; José de \& Domingosa, A. (2012). Functional genomics studies of Rhipicephalus (Boophilus) annulatus ticks in response to infection with the cattle protozoan parasite, Babesia bigemina. Int. J. Parasitol., 42(2): 187-195

Calvete, C.; Estrada, R.; Lucientes, J. \& Estrada, A. (2003). Ectoparasite ticks and chewing lice of red-legged partridge, Alectoris rufa, in Spain. Med. Vet. Entomol., 17: 33-7.

Hamsíkova, Z.; Kazimírova, M.;Harustiakova, D.; Mahríkova, L; Slovák, M.; Berthova, L.; Kocianova, E \& Schnittger, L. (2016). Babesia spp. in ticks 
and wildlife in different habitat types of Slovakia. Parasites \& Vectors, 9: 292.

Hasle, G. (2013).Transport of Ixodid ticks and tick-borne pathogens by migratory birds. Front Cell Infect Microbiol., 3: 48.

Hasle, G.; Horak, I.G.; Grieve, G.; Leinaas, H.P. \& Clarke, F. (2009). Ticks collected from birds in northern South Africa, 20042006. Onderstepoort J. Vet., 76: 167-175.

Hasson, R.H. (2012).Tick distribution and infestation among sheep and cattle in Baghdad's south suburb. Kufa J. Vet. Med. Sci., 3(1): 77-90.

Hoogstraal, H.; Kaiser, M.N.; Traylor, M.A.; Gaber, S.; Guindy E. \& Gaber, S. (1963). Ticks (Ixodidae) on birds migrating from Europe and Asia to Africa. Bull. World Health Organ., 28: 235-262.

Hubalek, Z. (2004). An annotated checklist of pathogenic microorganisms associated with migratory birds. J. Wildl. Dis., 40: 639-659.

Jongean, F. \& Uilenberg, G. (2004).The global importance of ticks. Parasitology, 129: 3-14.

Mehl, R.; Michaelsen, J. \& Lid, G. (1984). Ticks (Acari, Ixodides) on migratory birds in Norway. Fauna Norv. Ser.B., 31: 46-58.

Mustafa, B.H.S. (2011). A study on epidemiology of hard tick (Ixodidae) in sheep and a trial of immunization of rabbits against (Hyalomma anatolicum anatolicum) in Sulaimani governorateKurdistan region-Iraq. Ph. D. Thesis. Coll. Agric., Univ. Sulaimani, Iraq: 37pp.

Oliver, Jr, J.H. (1989). Biology and Systematics of Ticks (Acari: Ixodida). Annu. Rev. Ecol. Syst., 20: 397-430.

Olsen, B.; Duffy, D.C.; Jaenson, T.G.T.; Gylfe, A.; Bonnedahl, J. \& Bergstrom, S. (1995) Trans- hemispheric exchange of lyme disease spirochetes by seabirds. J. Clin. Microbiol., 33(12): 3270-3274.

Ouhelli, H. \& Schein, E. (1988). Effect of temperature on transovarial transmission of Babesia bigemina (Smith and Kilborne,
1893) in Boophilus annulatus (Say, 1821). Vet. Parasitol., 26(3-4): 229-235.

Parola, P. \& Raoult, D. (2001). Ticks and tick borne bacterial diseases in humans: An emerging infectious threat. Clin. Infect. Dis..2 32(6): 897-928.

Peter, R.J.; Van den Bossche, P.; Penzhorn, B.L. \& Sharp, B. (2005). Tick, fly, and mosquito control lessons from the past, solutions for the future. Vet. Parasitol., 132: 205-215.

Rechav, Y. \& Fielden, L.J. (1997). The effect of various host species on the feeding performance of immature stages of the tick Hyalomma truncatum (Acari: Ixodidae). Exp. Appl. Acarol., 21(8): 551-559.

Scharf, W.C. (2004). Immature ticks on birds: Temporal abundance and reinfestation. Northeast. Nat., 11(2): 143-150.

Scott, M.C.; Rosen, M.E.; Hamer, S.A.; Baker, E.; Edwards, H.; Crowder, C.; Tsao, J.I. \& Hickling, G.J. (2010). High prevalence Borrelia miyamotoi infection among wild turkeys (Meleagris gallopavo) in Tennessee. J. Med. Entomol., 47: 12381242.

Toma, L, Mancini, F.; Di Luca, M.; Cecere, J.G.; Bianchi, R.; Khoury, C.; Quarchioni, E.; Manzia, F.; Rezza, G. \& Ciervo, A. (2014). Detection of microbial agents in ticks collected from migratory birds in central Italy. Vector Borne Zoonot. Dis., 14: 199-205.

Tuama, S.J.; Al-Zihiry, K.J.K. \& Al-Maliky, H.K. (2007). Ticks infesting some domestic animals in Thi-Qar Province, Southern Iraq. J. Missan Res., 4(7): 1-12

Walker, A.R.; Bouattour, A.; Camicas, J.L.; Estrada- Pena, A.; Horak, I.G.; Latif, A.; Pegram, R.G. \& Preston, P.M. (2003). Ticks of domestic animals in Africa: A guide to identification of species. Bioscience Reports: 221pp. 